\title{
The efficacy of current-used risk factors for metastasis and the effectiveness of additional surgical resection in pT1b esophageal squamous cell carcinoma after endoscopic resection: A multi- institutional retrospective study in China
}

\section{Xuemin Xue}

National Cancer Center/National Clinical Reserch Center for Cancer/Cancer Hospital, Chinese Academy of Medical Sciences and Peking Union Medical College

Qi Sun

Nanjing Drum Tower Hospital, the affiliated Hospital of Nanjing University Medical School

\section{Dongxian Jiang}

Zhongshan Hospital, Fudan University

\section{Xinran Wang}

The Fourth Hospital of Hebei Medical University

\section{Yong Liu}

National Cancer Center/National Clinical Research Center for Cancer/Cancer Hospital, Chinese Academy of Medical Sciences and Peking Union Medical College

\section{Changyuan Guo}

National Cancer Center/Natinal Clinical Research Center for Cancer/Cancer Hospital, Chinese Academy of Medical Sciences and Peking Union Medical College

\section{Linxiu Liu}

National Cancer Center/National Clinical Research Center for Cancer/Cancer Hospital, Chinses Academy of Medical Sciences and Peking Union Medical College

\section{$\mathrm{Na}$ Cheng}

National Cancer Center/National Clinical Research Center for Cancer/Cancer Hospitla, Chinese Academy of Medical Sciences and Peking Union Medical College

\section{Guiqi Wang}

National Cancer Center/National Clinical Research Center for Cancer/Cancer Hospital, Chinese Academy of Medical Sciences and Peking Union Medical College

\section{Yueping Liu}

The fourth hospital of Hebei Medical University

\section{Yingyong Hou}

Zhongshan Hospital, Fudan University 


\section{Xiangshan Fan}

Nanjing Drum Tower Hospital, the affiliated Hospital of Nanjing University Medical School liyan xue ( $\nabla$ xuely@cicams.ac.cn )

Cancer Hospital Chinese Academy of Medical Sciences https://orcid.org/0000-0001-7762-9390

\section{Research Article}

Keywords: esophageal squamous cell carcinoma, Endoscopic resection, surgical resection

Posted Date: February 24th, 2021

DOl: https://doi.org/10.21203/rs.3.rs-250283/v1

License: (c) (i) This work is licensed under a Creative Commons Attribution 4.0 International License. Read Full License 


\section{Abstract \\ Purpose}

ER-treated patients with $\mathrm{pT} 1 \mathrm{~b}$ ESCC were strongly recommended to receive additional treatments, mainly radical surgical resection (SR). In view of high morbidity and mortality of additional SR treatment, this recommendation remained open to debate. Herein, our research aimed to access the efficacy of current risk predictors for metastasis based on the histological findings in ER specimens, and the effectiveness of additional SR.

\section{Methods}

We conducted a retrospective study of ER-treated pT1b ESCC patients with $(n=42)$ and without $(n=124)$ additional SR from 2007 to 2018 in China. Lymph node metastasis \& distant organ metastasis (LNM\&DOM) reflecting the overall metastasis risk of ESCC after ER treatment were used. The relationships between clinicopathological parameters and metastasis were assessed. And Overall survival(OS) and progression-free survival (PFS) were also analyzed.

\section{Results}

Patients with submucosal invasion depth $(\mathrm{SMI}) \geq 200 \mu \mathrm{m}$ didn't demonstrate significant difference in

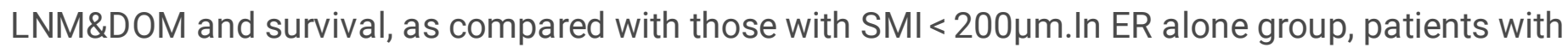
vertical margin $(\mathrm{VM})(+)$ showed worse PFS than those with $\mathrm{VM}(-)(p=0.008)$. More strikingly, for patients in low-risk group who had LVI(-) and VM(-), ER + SR didn't significantly prolong their PFS $(p=0.120)$ but significantly shorter their OS $(p<0.010)$ as compared with ER alone treatment.

\section{Conclusions}

SMI $\geq 200 \mu \mathrm{m}$ isn't a sensitive and predictive indicator for both LNM\&DOM and survival for patients with ER treatment. More strikingly, additional SR is not an optimal therapeutic selection for ER-treated $\mathrm{pT} 1 \mathrm{~b}$ ESCC in low-risk group who had LVI(-) and VM(-).

\section{Introduction}

Endoscopic resection (ER) has become gold standard for the treatment of superficial esophageal squamous cell carcinoma (ESCC) due to safe, short recovery time and the preservation of esophagus, as compared with esophageal radical surgical resection (SR). Unfortunately, data from radical SR demonstrated that the incidence of lymph node metastasis (LNM) in ESCC with sm1, sm2 and sm3 invasion (superficial, middle and deep thirds of the submucosa, respectively) were $16.92 \%-24.0 \%$, 13.73\%-20.5\% and 34.3\%-43.8\%,respectively(B Li, et al. 2013, Y Zhou, et al. 2016, Y Zhou, et al. 2019). 
Meanwhile, data from ER revealed that the cumulative 5-year metastasis rates of ESCC with sm1 (submucosal invasion depth $(\mathrm{SMI})<200 \mu \mathrm{m})$ and sm2 $(\mathrm{SMI} \geq 200 \mu \mathrm{m})$ were approximately $7.7 \%$ and $36.2 \%$, respectively ( $T$ Yamashina, et al. 2013). Based on these data, ER-treated pT1b ESCC were strongly recommended to receive additional treatments for curative intent according to 2020 Japan Gastroenterological Endoscopy Society (JGES) guideline for esophageal cancer(R Ishihara, et al. 2020). However, given the evidence were largely originated from small-size retrospective studies, this recommendation remained open to debate. And this new recommendation seems to be more aggressive than the previous 2017 Japanese Esophageal Society (JES) guideline, which recommended patients with high-risk factors,SMI $\geq 200 \mu \mathrm{m}$ and/or lymphovascular invasion (LVI) (+), for additional treatment(S Japan Esophageal 2017).

In terms of curability, additional SR would be a better choice than ER. However, the occurrence of related complications, such as anastomotic leak and reflux, would increase correspondingly, and decrease the patient's long-term quality of life ( $Y$ Zhang, et al. 2019, Y Koterazawa, et al. 2018, H Saeki, et al. 2015). Moreover, based on stringent selection criteria in routine clinical practice, only patients without obvious LNM and deep invasion detected by preoperative imaging and endoscopic examinations underwent ER. Thus, less LNM can be expected in ER-treated patients than that in SR-treated patients ( $R$ Ishihara, et al. 2020, Y Zhang, et al. 2019). Therefore, ER-treated pT1b ESCC patients represents a distinct subgroup of patients with relatively less aggressive clinical course than those SR-treated counterparts.

Herein, our research conduct the largest study which enrolled 166 cases of pT1b ER-treated patients with or without additional SR, aiming to access the efficacy of current risk predictors for metastasis based on the histological findings in ER specimens, and the effectiveness of additional SR.

\section{Materials And Methods}

\section{Patients}

Initially, 173 cases of ER-treated pT1b ESCC from 2007 to 2018 without preoperative or postoperative radio chemotherapy were evaluated. They were diagnosed at National Cancer Center/National Clinical Research Center for Cancer/Cancer Hospital. Based on exclusion criterion, 124 cases were eventually included in ER group (Fig. 1).

Meanwhile, between 2007 and 2018, 62 cases of pT1b patients treated by ER followed by SR were initially selected from four hospitals. They all underwent two-field lymphadenectomy. According to exclusion criterion, we finally enrolled 42 cases for ER+SR group (Fig. 1), including National Cancer Center/National Clinical Research Center for Cancer/Cancer Hospital( $n=20)$, Nanjing Drum Tower Hospital $(n=8)$, Shanghai Zhongshan Hospital $(n=8)$ and the Fourth Hospital of Hebei Medical University $(n=6)$.

The exclusion criteria are as follows: 1) Combination with SCC of other sites, 2) Second primary ESCC, 3) Combination with other type of cancer, 4) Carcinoma with basaloid or spindle cell subtypes, 5) No follow- 
up data, 6) Time of follow-up < 6 months, 7) Incomplete clinical data (e.g. no SMI depth value).

\section{Clinicopathological evaluation and follow up}

The clinicopathological variables in two cohorts were evaluated, including age, gender, tumor location, tumor poor differentiation (PD), LVI, and SMI.

More importantly, both synchronous and metachronous metastasis of lymph node and distant organ were integrated into the data of LNM\&DOM (lymph node metastasis \& distant organ metastasis) in order to reflects the overall metastasis risk of ESCC after ER treatment. Meanwhile, patients with follow-up time less than 6 months were excluded from our analysis.

\section{Statistical Analysis}

The baseline characteristics between ER alone and ER+SR treatment were analyzed by Chi-square test or Mann-Whitney test. The odd ratio (OR) for LNM\&DOM of each parameter was calculated by univariate logistic regression analysis firstly, in which parameters with $p<0.05$ were evaluated together using multivariate logistic regression analysis.

The times of overall survival (OS) and progression-free survival (PFS) were defined from the date of ER to the date of death/event or the last follow-up. The day of last follow-up was Janunary $9^{\text {st }} 2021$.The survivals were compared by using Log-Rank and Cox regression analysis. The survival curve was plotted using Kaplan-Meier procedure.

All statistical analysis was two sided and $p<0.05$ was defined as significance. All above statistical analyses were run in $\mathrm{R} 3.6 .0$ statistical software.

\section{Results}

\section{The baseline characteristics of pT1b ER ESCC}

The characteristics of ER-treated patients were summarized in Table 1. All of them were diagnosed as common squamous cell carcinoma, excluding basaloid or spindle cell subtypes. And all of them were confirmed as $\mathrm{pT} 1 \mathrm{~b}$ based on the ER specimens. 
Table 1

The baseline characteristics of 166 cases of pT1b ESCC with endoscopic resection

$\begin{array}{lll}\text { ER }+\mathrm{SR} & \text { ER } & \begin{array}{l}\text { P_value } \\ \text { (Chi-squared test) }\end{array} \\ (\mathrm{n}=42) & (\mathrm{n}=124) & \end{array}$

Age

Median [IQR] $\quad 60.5[55.00,64.00] \quad 62[57.00,67.00] \quad 0.101^{\#}$

Sex

\begin{tabular}{llll} 
Female & $5(11.9 \%)$ & $31(25.0 \%)$ & 0.118 \\
\cline { 1 - 2 } Male & $37(88.1 \%)$ & $93(75.0 \%)$ &
\end{tabular}

Submucosal invasion depth $\geq 200 \mu \mathrm{m}$

\begin{tabular}{llll} 
Negative & $5(11.9 \%)$ & $33(26.6 \%)$ & 0.08 \\
\cline { 1 - 2 } Positive & $37(88.1 \%)$ & $91(73.4 \%)$ &
\end{tabular}

VM

$\begin{array}{llll}\text { Negative } & 32(76.2 \%) & 121(97.6 \%) & <0.001\end{array}$

LVI

\begin{tabular}{llll} 
Negative & $29(69.0 \%)$ & $108(87.1 \%)$ & 0.015 \\
\cline { 1 - 2 } Positive & $13(31.0 \%)$ & $16(12.9 \%)$ &
\end{tabular}

PD

\begin{tabular}{llll} 
Negative & $30(71.4 \%)$ & $72(58.1 \%)$ & 0.176 \\
\cline { 1 - 2 } Positive & $12(28.6 \%)$ & $52(41.9 \%)$ &
\end{tabular}

Location

\begin{tabular}{llll} 
Upper & $7(16.7 \%)$ & $17(13.7 \%)$ & 0.319 \\
\hline Middle & $9(21.4 \%)$ & $42(33.9 \%)$ & \\
\hline Lower & $26(61.9 \%)$ & $65(52.4 \%)$ &
\end{tabular}

\section{LNM\&DOM}

IQR, interquartile range; PD,poor differentiation; LVI,lymph-vascular invasion; VM, vertical margin; LNM\&DOM, lymph node metastasis \& distant organ metastasis.

\#, Mann-Whitney test 


\begin{tabular}{|cccc|}
\hline & ER + SR & ER & $\begin{array}{l}\text { P_value } \\
\text { (Chi-squared test) }\end{array}$ \\
\hline & $(\mathbf{n = 4 2 )}$ & $(\mathbf{n = 1 2 4 )}$ & $<0.001$ \\
\hline Negative & $28(66.7 \%)$ & $113(91.1 \%)$ & \\
\hline Positive & $14(33.3 \%)$ & $11(8.9 \%)$ & \\
\hline $\begin{array}{l}\text { IQR, interquartile range; PD,poor differentiation; LVI,lymph-vascular invasion; VM, vertical margin; } \\
\text { LNM\&DOM, lymph node metastasis \& distant organ metastasis. }\end{array}$ & \\
\hline \#, Mann-Whitney test & & \\
\hline
\end{tabular}

The incidences of LVI (31.1\%) and $\mathrm{VM}(+)(23.8 \%)$ in $\mathrm{ER}+\mathrm{SR}$ group were significantly higher than those in ER alone group. Accordingly, the rate of LNM\&DOM in ER + SR group (33.3\%) was nearly four times as many as that in ER alone group (8.9\%).

\section{Analysis Of Lnm\&dom In Patients With Er + sr Treatment}

In ER + SR group, VM $(p=0.049), \operatorname{LVI}(p=0.002), P D(p=0.006)$ and number of resected lymph nodes $(p=$ $0.021)$ were significantly associated with LNM\&DOM. However, based on multivariate logistic regression analysis, only LVI was an independent predictor for LNM\&DOM ( $p=0.035)$, as shown in Table 2. 
Table 2

Logistic regression analysis for LNM\&DOM in $\mathrm{pT} 1 \mathrm{~b}$ ER $+\mathrm{SR}$ specimens

\begin{tabular}{|c|c|c|c|c|c|}
\hline LNM\&DOM & & $O R \_U(95 \% \mathrm{Cl})$ & & OR M & \\
\hline $\begin{array}{l}\text { Negative }(n= \\
28)\end{array}$ & $\begin{array}{l}\text { Positive }(n= \\
14)\end{array}$ & & & & \\
\hline
\end{tabular}

Age

$\begin{array}{lllll}\text { Median } & 61 & 58 & 0.92(0.84- & 0.078 \\ {[\text { IQR] }} & {[58,65]} & {[49,62]} & 1.01) & \end{array}$

Sex

Female $\quad 5(100.0 \%) \quad 0(0.0 \%)$

$\begin{array}{llll}\text { Male } & 23(62.2 \%) & 14(37.8 \%) & \text { NA }\end{array}$

Submucosal invasion depth $\geq 200 \mu m$

$\begin{array}{lllll}\text { Negative } & 4(80.0 \%) & 1(20.0 \%) & 1 & \\ \text { Positive } & 24(64.9 \%) & 13(35.1 \%) & \begin{array}{l}2.17(0.22- \\ 21.46)\end{array} & 0.509\end{array}$

VM

$\begin{array}{lllllll}\text { Negative } & 24(75.0 \%) & 8(25.0 \%) & 1 & 1 & \\ \text { Positive } & 4(40.0 \%) & 6(60.0 \%) & \begin{array}{l}4.5(1.01- \\ 20.11)\end{array} & 0.049 & \begin{array}{l}4.48(0.71- \\ 28.37)\end{array} & 0.112\end{array}$

LVI

$\begin{array}{lllllll}\text { Negative } & 24(82.8 \%) & 5(17.2 \%) & 1 & & & \\ \text { Positive } & 4(30.8 \%) & 9(69.2 \%) & \begin{array}{l}10.8(2.36- \\ 49.46)\end{array} & 0.002 & \begin{array}{l}6.76(1.15- \\ 39.9)\end{array} & 0.035\end{array}$

PD

$\begin{array}{lllllll}\text { Negative } & 24(80.0 \%) & 6(20.0 \%) & 1 & & & \\ \text { Positive } & 4(33.3 \%) & 8(66.7 \%) & 8(1.79-35.74) & 0.006 & 2.87(0.46- & 0.259\end{array}$

Location

$\begin{array}{lll}\text { Upper } & 5(71.4 \%) & 2(28.6 \%) \\ \end{array}$

NA, not applicable;

OR_U, Odd ratio by univariate analysis; OR_M, Odd ratio by multivariate analysis;IQR, interquartile range; PD,poor differentiation; LVI,lymph-vascular invasion; VM, vertical margin; LNM\&DOM, lymph node metastasis \& distant organ metastasis. 


\begin{tabular}{|c|c|c|c|c|c|c|}
\hline & \multicolumn{2}{|l|}{ LNM\&DOM } & \multirow[t]{2}{*}{$O R \_U(95 \% \mathrm{Cl})$} & \multirow{2}{*}{$\begin{array}{l}p_{-} \\
\text {value }\end{array}$} & \multirow{2}{*}{$\begin{array}{l}\text { ORM } M \\
(95 \% C I)\end{array}$} & \multirow{2}{*}{$\begin{array}{l}p_{-} \\
\text {value }\end{array}$} \\
\hline & $\begin{array}{l}\text { Negative }(n= \\
28)\end{array}$ & $\begin{array}{l}\text { Positive ( } n= \\
\text { 14) }\end{array}$ & & & & \\
\hline Middle & $7(77.8 \%)$ & $2(22.2 \%)$ & $\begin{array}{l}0.714(0.07- \\
6.92)\end{array}$ & 0.772 & & \\
\hline Lower & $16(61.5 \%)$ & $10(38.5 \%)$ & $\begin{array}{l}1.562(0.25- \\
9.65)\end{array}$ & 0.631 & & \\
\hline \multicolumn{7}{|c|}{ Number of resected lymph nodes } \\
\hline \multirow{2}{*}{$\begin{array}{l}\text { Median } \\
\text { [IQR] }\end{array}$} & 16.0 & 22.5 & \multirow{2}{*}{$\begin{array}{l}1.111(1.02- \\
1.22)\end{array}$} & \multirow[t]{2}{*}{0.021} & \multirow{2}{*}{$\begin{array}{l}1.06(0.95- \\
1.19)\end{array}$} & \multirow[t]{2}{*}{0.270} \\
\hline & {$[13.0,20.3]$} & {$[16.3,31.5]$} & & & & \\
\hline \multicolumn{7}{|c|}{ NA, not applicable; } \\
\hline $\begin{array}{l}\text { OR_U, Odd } \\
\text { range; PD,p } \\
\text { node metas }\end{array}$ & $\begin{array}{l}\text { Inivariate } \\
\text { rentiation; }\end{array}$ & $\begin{array}{l}\text { sis; OR_M, Oc } \\
\text { mph-vascula }\end{array}$ & $\begin{array}{l}\text { atio by multi } \\
\text { vasion; VM, }\end{array}$ & $\begin{array}{l}\text { e ana } \\
\text { al mar }\end{array}$ & $\begin{array}{l}\text { sis;IQR, inter } \\
\text { n; LNM\&DOI }\end{array}$ & $\begin{array}{l}\text { ile } \\
\text { nph }\end{array}$ \\
\hline
\end{tabular}

\section{Analysis Of Lnm\&dom In Patients With Er Alone Treatment}

In ER alone group, none of the clinicopathological characteristics was correlated with LNM\&DOM, as shown in Table 3. 
Table 3

Logistic regression analysis for LNM\&DOM in $\mathrm{pT} 1 \mathrm{~b}$ ER specimens

LNM\&DOM

Negative $(n=113) \quad$ Positive $(n=12)$
OR $U(95 \% \mathrm{Cl})$

p_value

\section{Age}

Median [IQR] 62[57, 67]

$61[58,66]$

$0.994(0.921-1.072)$

0.870

Sex

Female

$29(93.5 \%)$

$2(6.5 \%)$

1

Male

$84(90.3 \%)$

$9(9.7 \%)$

$1.554(0.317-7.613)$

0.587

Submucosal invasion depth $\geq 200 \mu \mathrm{m}$

Negative

$31(93.9 \%)$

$2(6.1 \%)$

1

Positive

$82(90.1 \%)$

$9(9.9 \%)$

$1.701(0.348-8.317)$

0.512

VM

Negative

Positive

LVI

Negative

Positive

$99(91.7 \%)$

$14(87.5 \%)$

PD

Negative

Positive

68 (94.4\%)

45 (86.5\%)

15 (13.3\%)

41 (36.3\%)

57 (50.4\%)

Lower

Upper

Middle

Lower

OR_U, Odd ratio by univariate analysis; IQR, interquartile range; PD,poor differentiation; $L V I$, lymphvascular invasion; VM, vertical margin; LNM\&DOM, lymph node metastasis \& distant organ metastasis. 
As to PFS, patients with PD(+) had shorter PFS than those with PD $(-)$ in ER + SR group $(p=0.022)$, as shown in Table 4. More importantly, in ER specimens, patients with VM (+) showed worse PFS than those with $\mathrm{VM}(-)$ in ER alone group $(\mathrm{p}=0.008)$, but no significant difference was found in ER $+\mathrm{SR}$ group $(p=$ $0.640)$, as shown in Table 4.

Table 4

Cox regression analysis for PFS in ER + SR and ER alone groups

\begin{tabular}{|c|c|c|c|c|}
\hline & \multicolumn{2}{|l|}{$\mathrm{ER}+\mathrm{SR}$} & \multicolumn{2}{|l|}{ ER alone } \\
\hline & HR_U $(95 \% \mathrm{Cl})$ & p_value & HR_U (95\%Cl) & P_value \\
\hline Age (median [IQR]) & $\begin{array}{l}1.008(0.909- \\
1.117)\end{array}$ & 0.882 & $\begin{array}{l}0.989(0.926- \\
1.056)\end{array}$ & $0.734^{\#}$ \\
\hline Sex $=$ male & NA & NA & $\begin{array}{l}1.355(0.377- \\
4.863)\end{array}$ & 0.641 \\
\hline $\begin{array}{l}\text { Submucosal invasion depth } \geq \\
200 \mu \mathrm{m}\end{array}$ & $0.46(0.048-4.43)$ & 0.502 & $\begin{array}{l}2.257(0.505- \\
10.088)\end{array}$ & 0.287 \\
\hline VM = Positive & $\begin{array}{l}0.598(0.069- \\
5.167)\end{array}$ & 0.640 & $\begin{array}{l}7.621(1.684- \\
34.496)\end{array}$ & 0.008 \\
\hline LVI = Positive & $\begin{array}{l}2.271(0.452- \\
11.408)\end{array}$ & 0.319 & $\begin{array}{l}2.164(0.599- \\
7.814)\end{array}$ & 0.239 \\
\hline PD = Positive & $\begin{array}{l}13.389(1.464- \\
122.456)\end{array}$ & 0.022 & $\begin{array}{l}2.827(0.973- \\
8.21)\end{array}$ & 0.056 \\
\hline \multicolumn{5}{|l|}{ Location } \\
\hline Middle & $\begin{array}{l}1.129(0.063- \\
20.304)\end{array}$ & 0.934 & $\begin{array}{l}0.361(0.051- \\
2.567)\end{array}$ & 0.309 \\
\hline Lower & $\begin{array}{l}0.895(0.095- \\
8.412)\end{array}$ & 0.922 & $\begin{array}{l}1.545(0.338- \\
7.067)\end{array}$ & 0.575 \\
\hline \multicolumn{5}{|c|}{$\begin{array}{l}\text { NA, not applicable; HR_U, hazard ratio by univariate analysis; PD,poor differentiation; LVI,lymph- } \\
\text { vascular invasion; VM, vertical margin; LNM\&DOM, lymph node metastasis \& distant organ } \\
\text { metastasis. }\end{array}$} \\
\hline
\end{tabular}

The comparisons of OS and PFS between ER alone and ER + SR treatment in low- and high-risk groups

Based on the status of LVI and VM, the patients were divided into low and high-risk groups. Patients with both $\mathrm{LVI}(-)$ and $\mathrm{VM}(-)$ were put into low-risk group, and patients with $\mathrm{LVI}(+)$ and/or $\mathrm{VM}(+)$ were selected in the high-risk group.

Herein, in low-risk group, patients with ER + SR treatment demonstrated significantly worse OS than those with ER alone treatment (81.8\% and $98.0 \%$, respectively, at 5 years; Log-Rank: $p<0.010)$. While, no significant difference in PFS was found between these two treatments $(77.4 \%$ and $89.6 \%$, respectively, at 5 years; Log-Rank: $p=0.120$ ) (Fig. 2a). 
However, in high-risk group, patients with ER alone treatment tend to have worse OS as compared with those with ER + SR treatment ( $80.8 \%$ and $100 \%$,respectively, at 5 years), but the p-value didn't achieve statistical significance probably due to small sample size (Log-Rank: $p=0.160)$ (Fig. 2b). Moreover, no significant difference in PFS was found between these two treatments (Log-Rank: $p=0.370$ ) (Fig. 2b).

In low-risk group, PD was significantly correlated with treatment $(p=0.008)$ (Table 5). Thus, in order to eliminate potential impacts by PD, we identified an extremely low-risk group with $\mathrm{VM}(-), \mathrm{LVI}(-)$ and $\mathrm{PD}(-)$.And the results showed that patients with $\mathrm{ER}+\mathrm{SR}$ treatment still had significantly worse OS than those with ER alone treatment ( $88.9 \%$ and $100.0 \%$, respectively, at 5 years; Log-Rank: $P=0.020)$. While, no significant difference in PFS was found between these two treatments ( $90.9 \%$ and $92.7 \%$, respectively, at 5 years; Log-Rank: $p=0.890$ ) (Fig. 3).

Table 5

The baseline characteristics of patients in low-risk group with $\mathrm{LVI}(-)$ and VM(-)

\begin{tabular}{|c|c|c|c|}
\hline \multirow[t]{2}{*}{ Low-risk group } & ER & $E R+S R$ & \multirow{2}{*}{$\begin{array}{l}\text { p_value } \\
\text { (Chi-squared test) }\end{array}$} \\
\hline & $(n=106)$ & $(n=23)$ & \\
\hline \multicolumn{4}{|l|}{ Age } \\
\hline Median [IQR] & $62[57.00,67.00]$ & $60[55.00,65.00]$ & $0.201^{\#}$ \\
\hline \multicolumn{4}{|l|}{ Sex } \\
\hline Female & $29(27.4 \%)$ & $4(17.4 \%)$ & \\
\hline Male & $77(72.6 \%)$ & $19(82.6 \%)$ & 0.466 \\
\hline \multicolumn{4}{|c|}{ Submucosal invasion depth $\geq 200 \mu \mathrm{m}$} \\
\hline Negative & $29(27.4 \%)$ & $5(21.7 \%)$ & \\
\hline Positive & $77(72.6 \%)$ & $18(78.3 \%)$ & 0.769 \\
\hline \multicolumn{4}{|l|}{ PD } \\
\hline Negative & $63(59.4 \%)$ & $21(91.3 \%)$ & \\
\hline Positive & $43(40.6 \%)$ & $2(8.7 \%)$ & 0.008 \\
\hline \multicolumn{4}{|l|}{ Location } \\
\hline Upper & $15(14.2 \%)$ & $6(26.1 \%)$ & 0.320 \\
\hline Middle & $36(34.0 \%)$ & $8(34.8 \%)$ & \\
\hline Lower & $55(51.9 \%)$ & $9(39.1 \%)$ & \\
\hline
\end{tabular}




\section{Discussion}

The presence of metastasis of lymph node and/or distant organ is an unfavorable prognostic factor for survival of ESCC. Estimating the probability of LNM\&DOM in PT1 ESCC is crucial for further therapeutic selection after ER. In our study, the overall incidence of LNM\&DOM was $15.1 \%$ (25/166). This result was in line with the study of Yamashina T,et al., which showed 21.2\% (11/52) for their overall risk of metastasis. Moreover, our study revealed that the rate of LNM\&DOM in ER + SR group was significantly higher than that in ER alone group $(33.3 \%$ vs. $8.9 \%, p<0.001)$. This is mainly because patients who had high-risk factors in routine practice tend to receive aggressive additional SR, with the higher incidences of LVI (31.0\%) and VM (+) (23.8\%) in ER + SR group than those in ER alone group (Table 1).

Meanwhile, we were curious about the efficacy of current risk predictor for metastasis and survival based on the histopathological findings in ER specimens. LVI is a widely-accepted risk factor for metastasis in patients with ER(K Takahashi, et al. 2018). In our study, LVI was significantly associated with LNM\&DOM in ER + SR group ( $p=0.035)$, but not in ER alone group $(p=0.587)$ (Table 2 and Table 3$)$. Patients with $\mathrm{SMI} \geq 200 \mu \mathrm{m}$ didn't demonstrate significant difference in LNM\&DOM and survival(Table 2,Table 3 and Table 4) as compared with those with SMI $<200 \mu \mathrm{m}$.In the study of Yamashina T,et al., ESCC with SMI $\geq$ $200 \mu \mathrm{m}$ demonstrated significantly higher metastasis and poorer survival as compared with those with epithelium/lamina propria mucosae invasion. But it didn't show significant difference as compared with those with $\mathrm{SMI}<200 \mu \mathrm{m}$, demonstrating overlap of their $95 \% \mathrm{Cl}$ ranges of hazard ratio ( $\mathrm{T}$ Yamashina, et al. 2013). Part of the reasons for this phenomenon is that patients with too deep invasion were excluded from the ER treatment, leading to the shorter range of invasion depth in ER-treated cohort as compared to that in SR-treated counterparts. Therefore, $200 \mu \mathrm{m}$ may be not an optimal cutoff value for ER-treated pT1b patients to predict LNM\&DOM and survival.

Moreover, in ER alone group, patients with VM (+) showed worse PFS than those with VM(-) $(p=0.008)$, indicating potential remnant cancers which could result in recurrence of disease, and, correspondingly, worse PFS (Table 4).More interestingly, in ER + SR group, VM(+) didn't predict the worse PFS $(p=0.640)$ anymore, suggesting that additional SR may overcome the adverse effect of VM (+) in ER specimens. Thus, even though the residual cancer in VM sometimes can be eliminated by burning effect, its risk assessment in routine practice should be performed cautiously.

In our study, we were curious about the effectiveness of additional SR for PT1b ESCC, especially for those with LVI(-) and VM(-). Strikingly, for patients in low-risk group who had LVI(-) and VM(-), ER + SR didn't significantly prolong their PFS as compared with ER alone treatment $(77.4 \%$ and $89.6 \%$, respectively, at 5 years; Log-Rank: $p=0.120$ ) (Fig. 2a). But it demonstrated significantly shorter OS in $E R+S R$ group than that in ER alone group ( $81.8 \%$ and $98.0 \%$, respectively, at 5 years; Log-Rank: $P<0.010)$. These results strongly supported that patients in low-risk group could not get benefits from additional SR but harm of procedure-related complications or deaths(H Saeki, et al. 2015). And the results were similar in extremely low-risk group who had VM(-), LVI(-) and PD(-)(Fig. 3). Thus, additional SR after ER is not a reasonable option for these low-risk patients, avoiding overtreatment. 
To the best of our knowledge, this is the largest study enrolling 166 cases of pT1b ESCC after ER to evaluate the efficacy of current-used risk factors and the effectiveness of additional SR. However, some statistical bias may be in our study, such as retrospective study, a relatively short follow-up period and a relatively small sample size, which requires further investigation.

In conclusion, based on our study, SMI $\geq 200 \mu \mathrm{m}$ was a less sensitive and predictive indicator for both LNM\&DOM and survival for patients with ER treatment. More strikingly, for patients in low-risk group who had LVI(-) and VM(-), ER + SR didn't prolong their PFS but significantly shorten their OS as compared with ER alone treatment. Thus, additional SR is not an optimal therapeutic selection for low-risk group.

\section{Declarations}

Funding: This work was supported by grants from CAMS Innovation Fund for Medical Sciences (CIFMS) (Grant No. 2019-I2M-2-004 and 2016-I2M-3-005), and the National Natural Science Foundation of China (81402463)

Conflicts of interest/Competing interests: None.

Availability of data and material: Available.

Code availability: R 3.6.0 statistical software

Authors' contributions: XX, QS, DJ, XW and YL contributed to data collection and clinical follow-up. XX contributed to data analysis and manuscript writing. CG, LL and NC contributed to data interpretation. $\mathrm{GW}, \mathrm{YL}, \mathrm{YH}, \mathrm{XF}$ and $\mathrm{LX}$ contributed to study design, coordination, discussion and manuscript editing. All authors read and approved the final manuscript.

Ethics approval: Due to the retrospective study, the data regarding treatment and prognosis were acquired by means of medical record consultation and telephone conversation. Thus, the need for consent was waived by 1) the Independent Ethics Committee of Cancer Hospital, Chinese Academy of Medical Sciences, National GCP Center for Anticancer Drugs (20/197-2393), 2) The Ethics Committee of Nanjing Drum Tower Hospital of Nanjing University Medical School (2020-254-02), 3) The Ethics Committee of Zhongshan Hospital of Fudan University (B2020-313) and 4) The Ethics Committee of the Fourth Hospital of Hebei Medical University (2020ky121).

Consent to participate: Not applicable.

Consent for publication: Not applicable.

\section{References}

1. Li B, Chen H, Xiang J, Zhang Y, Kong Y, Garfield DH, Li H (2013) Prevalence of lymph node metastases in superficial esophageal squamous cell carcinoma. J Thorac Cardiovasc Surg 
146(5):1198-1203. https://doi.org/10.1016/j.jtcvs.2013.07.006

2. Zhou Y, Du J, Li H, Luo J, Chen L, Wang W (2016) Clinicopathologic analysis of lymph node status in superficial esophageal squamous carcinoma. World J Surg Oncol 14(1):259.

https://doi.org/10.1186/s12957-016-1016-0

3. Zhou Y, Du J, Wang Y, Li H, Ping G, Luo J, Chen L, Zhang S, Wang W (2019) Prediction of lymph node metastatic status in superficial esophageal squamous cell carcinoma using an assessment model combining clinical characteristics and pathologic results: A retrospective cohort study. Int J Surg 66:53-61. https://doi.org/10.1016/j.ijsu.2019.04.014

4. Yamashina T, Ishihara R, Nagai K, Matsuura N, Matsui F, Ito T, Fujii M, Yamamoto S, Hanaoka N, Takeuchi Y, Higashino K, Uedo N, lishi H (2013) Long-term outcome and metastatic risk after endoscopic resection of superficial esophageal squamous cell carcinoma. Am J Gastroenterol 108(4):544-551. https://doi.org/10.1038/ajg.2013.8

5. Ishihara R, Arima M, lizuka T, Oyama T, Katada C, Kato M, Goda K, Goto O, Tanaka K, Yano T, Yoshinaga S, Muto M, Kawakubo H, Fujishiro M, Yoshida M, Fujimoto K, Tajiri H, Inoue H, Japan Gastroenterological Endoscopy Society Guidelines Committee of ESDEMRfEC (2020) Endoscopic submucosal dissection/endoscopic mucosal resection guidelines for esophageal cancer. Dig Endosc 32(4):452-493. https://doi.org/10.1111/den.13654

6. Japan Esophageal S (2017) Japanese Classification of Esophageal Cancer, 11th Edition: part I. Esophagus : official journal of the Japan Esophageal Society 14(1):1-36. https://doi.org/10.1007/s10388-016-0551-7

7. Zhang Y, Ding H, Chen T, Zhang X, Chen WF, Li Q, Yao L, Korrapati P, Jin XJ, Zhang YX, Xu MD, Zhou PH (2019) Outcomes of Endoscopic Submucosal Dissection vs Esophagectomy for T1 Esophageal Squamous Cell Carcinoma in a Real-World Cohort. Clin Gastroenterol Hepatol 17(1):73-81 e73. https://doi.org/10.1016/j.cgh.2018.04.038

8. Koterazawa Y, Nakamura T, Oshikiri T, Kanaji S, Tanaka S, Ishida T, Yamashita K, Matsuda T, Morita Y, Suzuki S, Kakeji Y (2018) A comparison of the clinical outcomes of esophagectomy and chemoradiotherapy after noncurative endoscopic submucosal dissection for esophageal squamous cell carcinoma. Surgery today 48(8):783-789. https://doi.org/10.1007/s00595-018-1650-y

9. Saeki H, Watanabe M, Mine S, Shigaki H, Oya S, Ishiyama A, Tsuchida T, Fujisaki J, Baba H, Maehara $Y$, Sano T (2015) Esophagectomy for superficial esophageal cancer after non-curative endoscopic resection. Journal of gastroenterology 50(4):406-413. https://doi.org/10.1007/s00535-014-0983-6

10. Takahashi K, Hashimoto S, Mizuno KI, Kobayashi T, Tominaga K, Sato H, Kohisa J, Ikarashi S, Hayashi K, Takeuchi M, Yokoyama J, Kawai H, Sato Y, Kobayashi M, Terai S (2018) Management decision based on lymphovascular involvement leads to favorable outcomes after endoscopic treatment of esophageal squamous cell carcinoma. Endoscopy 50(7):662-670. https://doi.org/10.1055/s-0043-124433

\section{Figures}




\section{ER alone treatment}

PT1b ESCC treated by ER between 2007-2018
from our single institution.
$(n=173)$

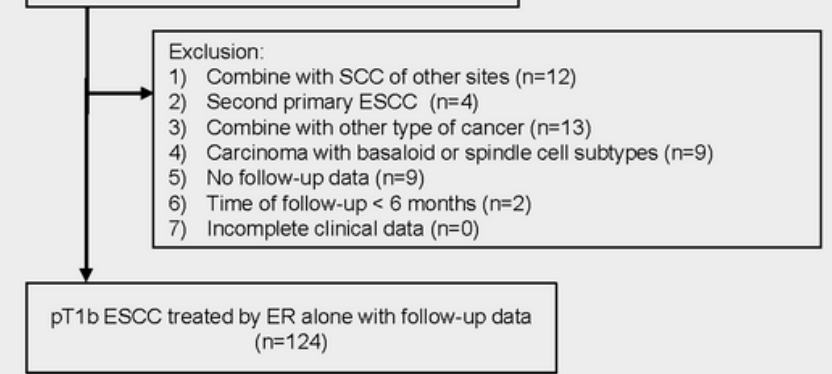

\section{$\mathrm{ER}+\mathrm{SR}$ treatment}

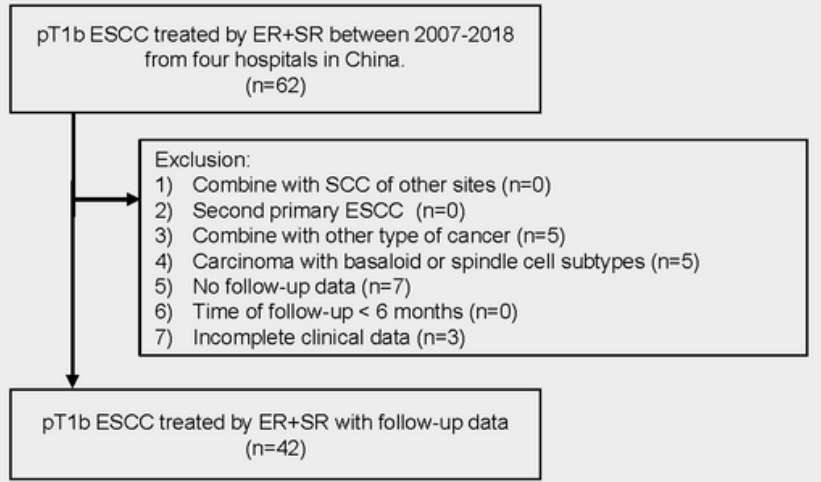

\section{Figure 1}

Flowchart of enrollment of patients 
a)

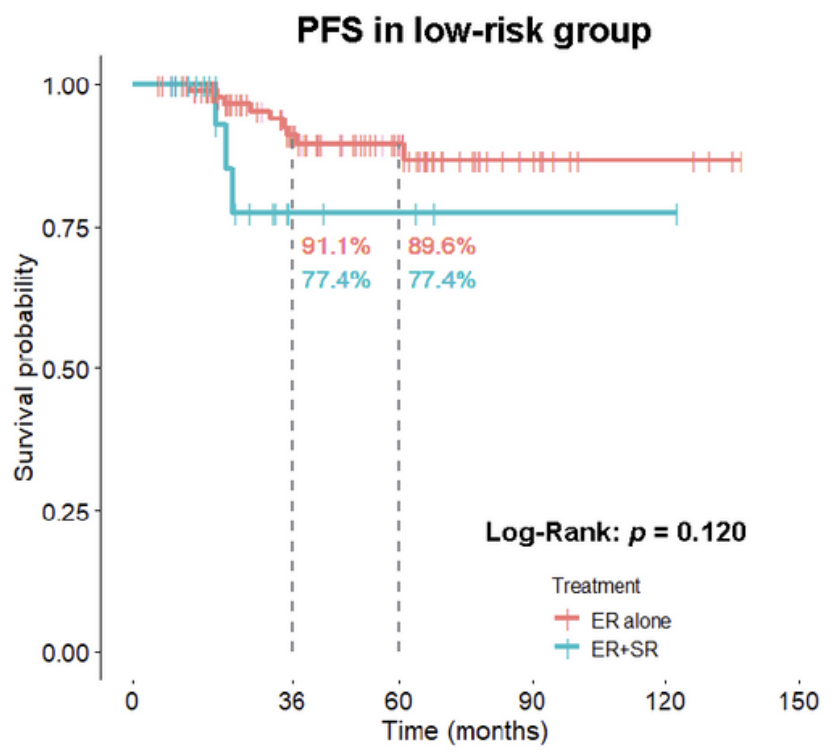

b)

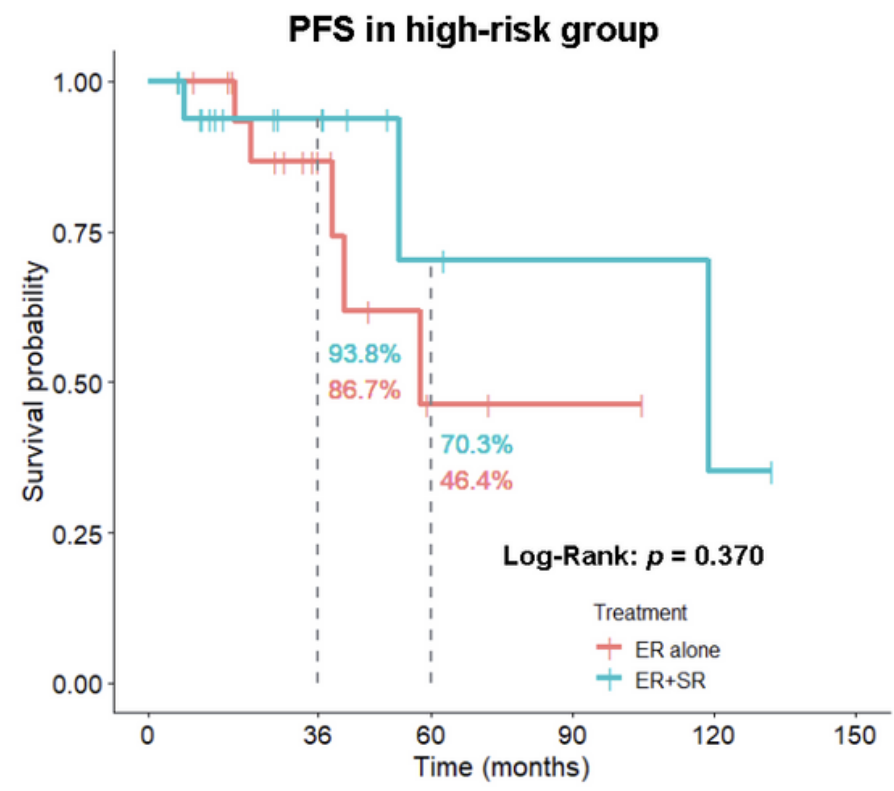

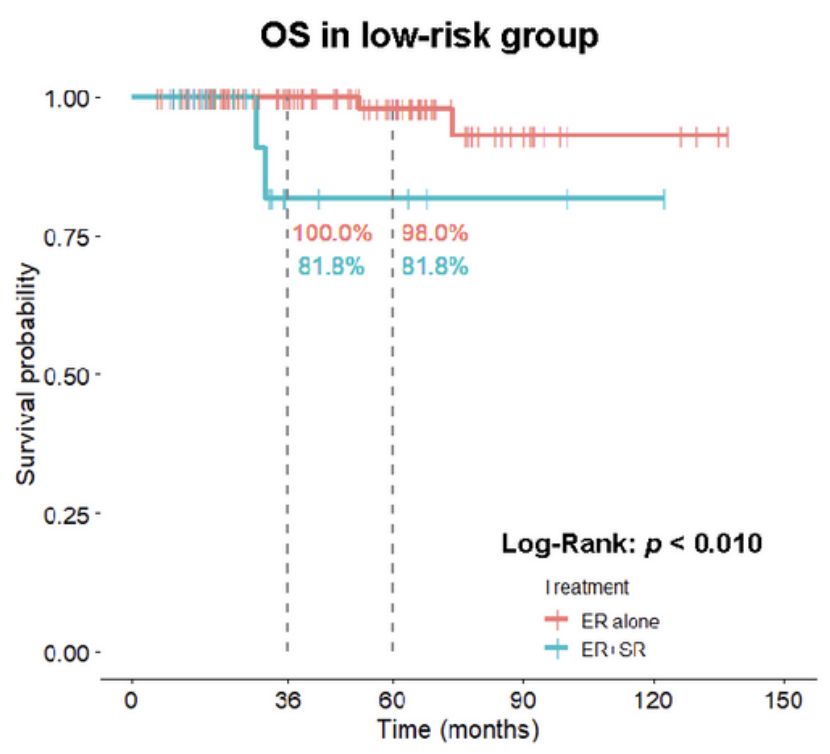

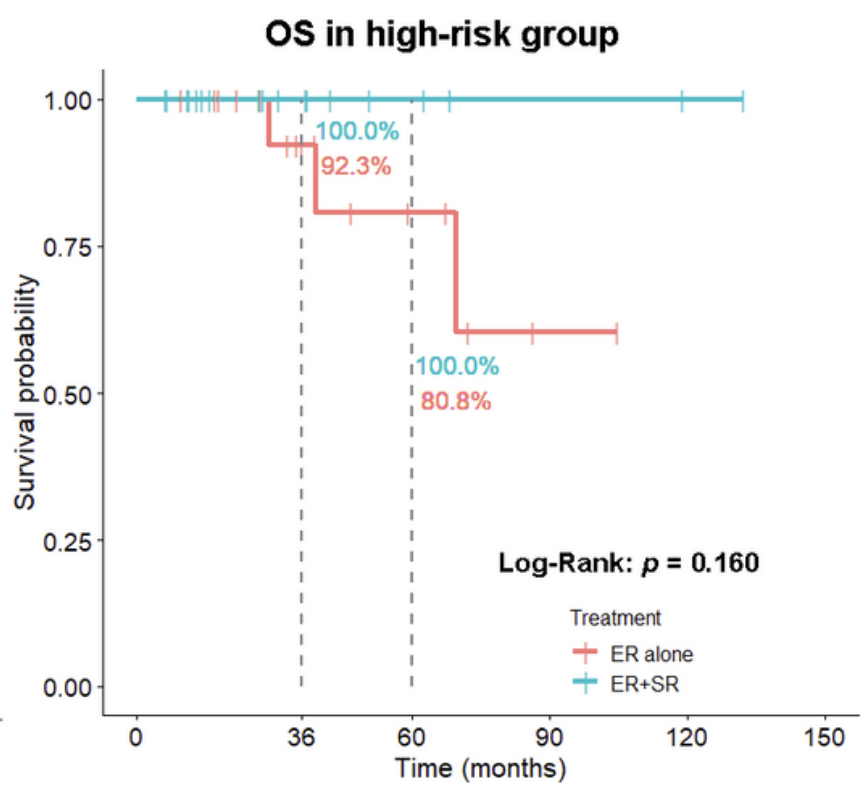

Figure 2

Comparisons of PFS and OS between ER alone and ER+SR treatment in low-risk group with LVI(-) and $\mathrm{VM}(-)(\mathrm{a})$ and high-risk group with $\mathrm{LVI}(+)$ and/or $\mathrm{VM}(+)(\mathrm{b})$ 

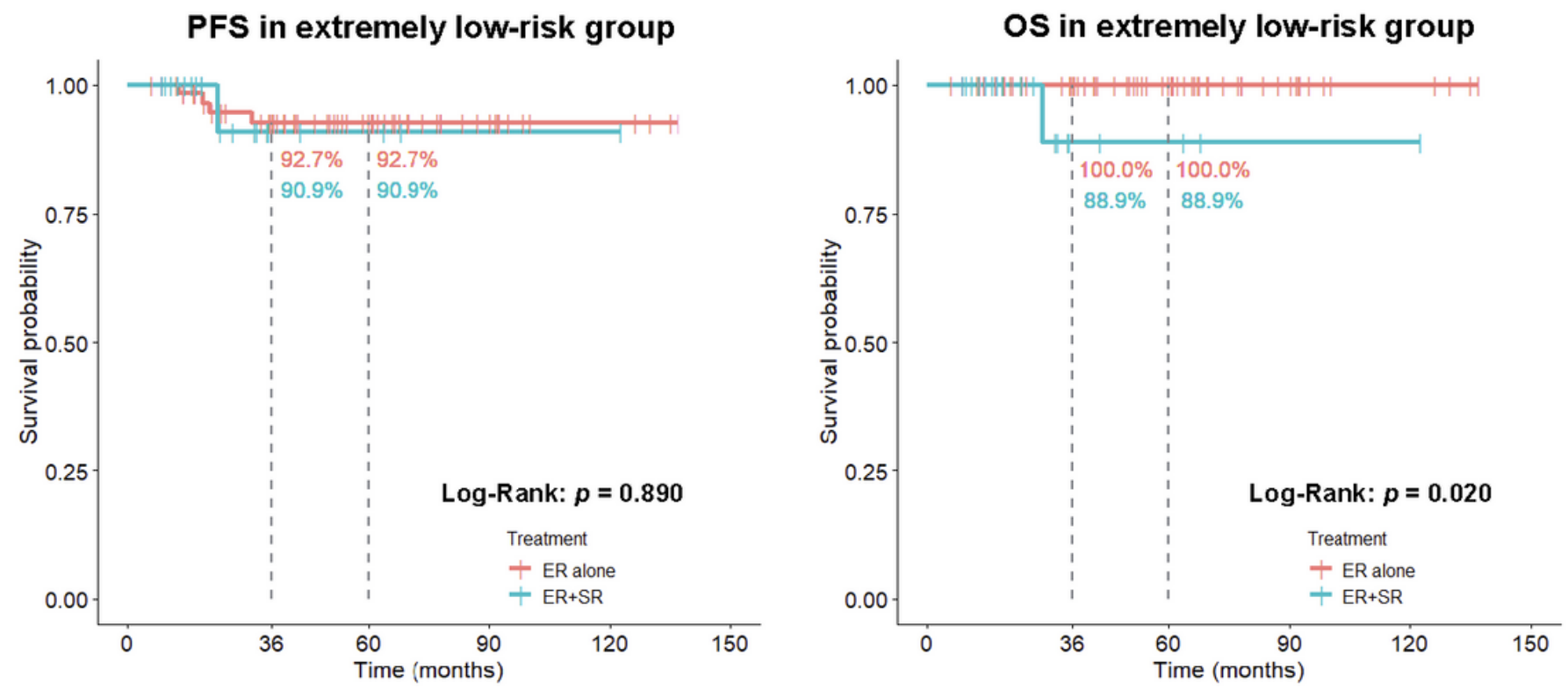

Figure 3

Comparisons of PFS and OS between ER alone and ER+SR treatment in extremely low-risk group with LVI(-), VM(-) and PD(-) 